\title{
Editors’ Foreword
}

\section{EMBRACING LINGUISTIC \& CULTURAL DIVERSITY THROUGH ENGLISH}

A section of this issue of LINGUACULTURE looks into the literary canon, the reworking of genres, the sense and concept of place and the process of remystifying it. It also tackles cultural specificity and dystopian standardization. It embraces and interconnects disciplines and genres in literature, film and the arts across cultures and languages, encompassing protean modern, postmodern and post-postmodern phenomena and processes, putting them into perspective from the vantage point of the present as we speak. Another section is dedicated to recent developments in linguistics, with two papers in Teaching English as a Foreign Language, one in translation studies and one in semantics, all of them reflecting their authors' enthusiasm both in research and in their profession as educators, translators and counselors. Given the fresh areas of interest that applied linguistics has gained, the proposed papers contribute valuable theoretical perspectives always doubled by pertinent suggestions for the practice of corpus selection, teaching techniques, translation approaches and an acute awareness of certain aspects of both English and other languages of academic activity that have long been awaiting a semantic meeting place as it were.

In the literary section, the four approaches to the American culture, literature and film gathered in this issue are largely informed by postcolonial theories, which are essentially revisionist. It is through their revisionism that they connect with an approach to the African writer Chinua Achebe, who wrote his emblematic groundbreaking novel Things Fall Apart, first published in 1958, and the other two novels in what became his African trilogy, in English. Significantly, Achebe chose for the title of his first published novel Things Fall Apart the verses of the poem The Second Coming by the Irish poet William Butler Yeats, thus bringinging not only the English language but also a whole tradition of literature written in English into a space of problematic contact and sore conflict, which gave postcolonial theory itself a fantastic impetus. At the same time, the five enthralling analyses of the concept of canon, of NativeAmerican identity, of the concept of the American West and its transformations through the cinema and of modern African literature written in English give us a 
sense of how our global world essentially molded by English feels both united and divided, even fragmented by its linguistic and cultural mold.

In his thought-provoking paper Redeeming the Canon: Transdisciplinary Collocations Felix Nicolau purports to examine the literary canon in the English speaking world, accounting for the impact of the latest developments in technology and media. He also brings forward new approaches to the canon, mainly those provided by the complex field of Cultural Studies, which opens it up to a diversity of criteria. Taking our essential need to communicate across cultures as a priority in building what he calls an "archcanon," Felix Nicolau raises questions and formulates possibilities that might underpin a revamped canon, "formed with an eye to the updated chart of values." (12) To the author's mind, the updates to the canon in the last twenty five years have been operated by "satellite-like and interdisciplinary canons." (14) Thus, the "arch-canon" becomes an all-encompassing structure irrigated by the big rivers and rivulets in the contemporary landscape of cultures and languages. Indeed, Bauman's metaphor of liquidity, which translates the condition of the turn of the 20th century culture, is most apt to shape a flexible canon that needs to accommodate polycentric and pluralistic cultural and aesthetic products drawing on digital literature, performatism, discourse theory and context.

Cornelia Vlaicu reads Louise Erdrich's National Book Award-winning novel The Round House, published in 2012, in terms that inform Felix Nicolau's view of the arch-canon. The author of the paper "There are many kinds of justice": Confessing Growing Up an Indian Legal Subject in Louise Erdrich's The Round House argues that the Ojibwe writer blows strictly defined categories of genres and reworks them from a Native American perspective to narrativize the condition of the American Indian people as "postcolonial." Referencing a vast bibliography that deals with the colonially-constructed stereotype of the Indian as "savage," Cornelia Vlaicu connects it with the postcolonial concept of the Other. Starting from Erdrich's own choice of the word "crusade" to talk about her book in an interview, the author argues that The Round House serves as "a vehicle for decolonization." (36) Joe, the novel's protagonist matches Vizenor's image of the "postindian warrior," (36) where he gains a voice which was refused to Geraldine, his mother, and with it he also gains agency. To all these layers of reading the main character in Erdrich's book, the author adds the archetype of the trickster.

Irina Chirica and Florina Năstase look into the West. While Irina Chirica's West is a cultural image undergoing a dynamic succession of changes from "The Garden of Eden" to the disenchentment with that archetype, Florina Năstase is concerned with its transformations through the cinema. Starting with Thomas Jefferson's Louisiana Purchase of 1803, Irina Chirica dwells on the expansion of the West as a region, which is also a cultural prototype of America, 
throughout American history. Arguing that Jefferson worked out a plan that involved the creation of territories which later became states, Irina Chirica shows that inside the larger West, there are several Wests: the prairie states of the Midwest (also called the "Bread Basket" of America), the Rocky Mountain states, the Pacific Northwest, the Southwest and California. Chirica analyzes the myths and images associated with the West in American culture, and the influence of Frederick Jackson Turner's essay dedicated to "the Frontier." She discusses the New Historicism approach and its critique of Turner. This becomes a background against which the author casts the reflection of the West in the visual arts (the major landscape painters and the work of the western movie director John Ford). Chirica's thesis is that the West is a construct of human experience and a cultural concept rather than a "place."

Florina Năstase's approach to Jim Jarmusch's Dead Man (1995) connects to both Irina Chirica's interest in the West and Cornelia Vlaicu's interest in a postcolonial revision of Americanness. Năstase's paper is informed by post-colonialism, especially Homi Bhabha's theory of hybridity, with particular emphasis on Native American identity. The author analyzes Jarmusch's film in the larger context of the western of the 1990s, a decade which embraces a rebirth of spiritualism through the genre of the "acid western." Dead Man is read as a film that showcases the return of the West as a cultural frontier that must be re-assimilated instead of rejected. In a compelling argument, Florina Năstase starts from the symbolic title to demonstrate that Dead Man is not so much a Western as it is an Eastern romance, a rite of passage framed as a journey towards death. The argument largely draws on assertions of director Jim Jarmusch, and various film critics who discuss the issue of the "acid western" as a genre.

In an embrace, the cultural-literary section of this issue of LINGUACULTURE closes on a postcolonial approach, an accolade of postcolonialism. Reflections on Cultural Specificity and Dystopian Standardization in Chinua Achebe's Novels written by Cristina and Liviu-Augustin Chifane aims at highlighting the stylistic differences between Achebe's novels of the African trilogy (Things Fall Apart - 1958, No Longer at Ease - 1960, Arrow of God 1964) and his subsequent masterpieces A Man of the People (1966) and Anthills of the Savannah (1987). The authors contend that while the African trilogy is underpinned by, and therefore has been analyzed in terms of culture-specific items and postcolonial issues, the other two novels acquire new dimensions, giving birth to what can be called dystopian standardization characteristic not only of a certain space or time, but of any society fighting corruption and abusive political systems inevitably leading to oppressive regimes, chaos and collapse. Ultimately, any reading is a journey, and the pattern of this one is an embrace of the world, its languages and its cultures, through English and beyond. 
Drawing on applied linguistics and ELT,, both Nicoleta Iftimie and Alyona Shyba, experienced educators and linguists, explore two essential factors that shape the teaching/learning continuum. Nicoleta Iftimie looks at the actual subject of teaching, the English language that now has acquired a new quality (Internatinal English) and has a new meaning for the students of English as a Second Language. Her starting point is Braj Bihari Kachru's theory of the English language spread unevenly in the multinational world of English speakers. Kachru's concentric circle model has important consequences for the teaching profession, especially in tertiary education. The author introduces the concept of glocalization as a merge between global English and localization (a term borrowed from computer studies and translation studies) as the necessary solution for teachers whose adult students of English have special learning needs that derive from their professional aspirations and the perspective of continuing their education in postgraduate programmes. The localization of teaching techniques and materials is not a new idea in itself, but Nicoleta Iftimie makes the interesting point that its context has changed considerably, as it is not one (standard) English that our students aspire to master, but any of the multiple Englishes used in research and international business.

In turn, Alyona Shyba presents another very recent development in TEFL and TESL, professional development as the result not of an external entity imposing centralized professional standards, but of internal reflection. Her hypothesis is tested twice on samples of teacher-trainees and in-service teaching staff in order to confirm the need for a clearer definition of a phrase circulated in reference to the pre-service and in-service teacher training - "professional competence development." Also, the author's study points to the concrete changes that need to be implemented in the process of teacher training starting from updating the actual techniques and adopting new technologies and going as far as making professional development a coherent policy in education.

With Ioana Păștinaru the focus shifts to translation, but not outside the university education sphere. She undertakes a massive effort of reviewing the English versions of a number of university official websites in an attempt to tackle the source of a number of malfunctions in the process of decoding a target text on the part of a large and very diverse audience of international students. Her methodology relies on Javier Franco Axielá's inventory of translation strategies, which she applies on a corpus of university websites in the original language (French, Spanish, Portuguese, Italian) and in English. The author emphasizes the cultural dimension of the translation challenges under investigation, and the risks such challenges entail for international students in terms of both educational opportunities and public relations. Ioana Păștinaru is also an experinced translator and, so, very well qualified to make suggestions meant to explicate ambiguities, lack of reference, or cultural misunderstandings. Also, the analysis reveals certain preferences for some translation strategies, and 
the author's critique aptly records the trend while discussing the impact some choices have as reflected in the target audience's reception.

Alexandra Stan's interest in the students' perception of English takes a different turn. University programmes that include (non-philological) courses of English create a necessary focus on specialized English. The author chooses the field of forestry and makes a demonstration of semantic analysis for a number of lexemes to show the differences in the meaning of words that students perceive to be synonyms between Romanian and English. The special circumstance of these students is that the challenging lexemes under investigation are recognized as belonging to the general core of frequently used terms (also present in the syllabus of pre-university courses of English due to their relatively high frequency) but cross the border to specialized terminology when fulfilling certain semantic features. The author aptly comments on the presence of the selected forestry terms in both general linguistic dictionaries and in specialized glossaries comparing the lexicographic and terminological definitions in both English and Romanian as an effort to help students of ESP to perceive the specialized terminology with a higher degree of accuracy.

The authors in this section share their preoccupation for the way English is perceived by university students (whether national or international), which makes their contribution to LINGUACULTURE all the more relevant. We, and they, are confident that, between theoretical and applied linguistics, the discussion on the status and scope of English will invite more and more participants as Kachru's outer circle of users outnumbers the inner core.

Dana Janeta BĂDULESCU Oana-Maria FRANȚESCU 